\title{
MECHANICAL AND THERMAL PROPERTIES OF COMPOSITES FROM UNSATURATED POLYESTER FILLED WITH OIL PALM ASH
}

\author{
M.S. Ibrahim ${ }^{1}$, S.M. Sapuan ${ }^{2}$ and A.A. Faieza ${ }^{2}$ \\ ${ }^{1}$ Advanced Material and Nanotechnology Laboratory, \\ Institute of Advanced Technology (ITMA), Universiti Putra Malaysia, \\ 43400 UPM Serdang, Selangor, Malaysia \\ ${ }^{2}$ Department of Mechanical and Manufacturing Engineering, \\ Universiti Putra Malaysia,43400 UPM Serdang, Selangor, Malaysia \\ Email:mshukriibrahim@gmail.com
}

\begin{abstract}
Oil palm ash (OPA) is available in abundance, is renewable, can be obtained at no cost and shows good performance at high thermal conditions. Combinations of the unsaturated polyester with natural fillers have been reported to improve the mechanical and thermal properties of composites. Utilisation of oil palm ash as a filler in the manufacture of polymer composites can significantly reduce the requirement for other binders or matrixes of composite materials. This research uses oil palm ash as a filler to form composites through the investigation of the effect of different contents of filler on the properties of OPA-filled unsaturated polyester (UP/OPA) composites. The effect of different volume fractions, i.e., $0,10,20$ and 30 vol.\% of oil palm ash introduced into $100,90,80$ and 70 vol.\% of an unsaturated polyester matrix on the composite mechanical properties, i.e., tensile and flexural, has been studied, together with thermal gravimetric analysis (TGA) and differential scanning calorimetric (DSC). Specimens were prepared using compression moulding techniques based on the ASTM D790 and D5083 standards for flexural and tensile tests, respectively. The tensile and flexural mechanical properties of UP/OPA composites were improved in modulus by increasing the filler content. Thermal stability of the composites increased as the OPA filler content was increased, which was a logical consequence because of the high thermal stability of the silica compound of the OPA filler compared with that of the UP matrix. The results from the surface electron microscope (SEM) analysis were the extension of mechanical and thermal tests.
\end{abstract}

Keywords: Oil palm ash, unsaturated polyester, filled composites, mechanical properties, thermal properties.

\section{INTRODUCTION}

Increasing awareness among the world's population to protect our environment has promoted an intensive use of biomass wastes. The agriculture industry in Malaysia with its more than 6 million hectares of plantation, produces over 100 million tons of biomass. The potential of using agricultural waste, such as sisal, jute, pineapple leaves, banana stems, oil palm, rice hulls and sugar palm as fillers is being explored. These biomass residues are all mostly available in abundance, can be obtained for little or no cost and are renewable throughout the whole year in countries like Malaysia (Oksman, Wallström, Berglund, \& Romildo, 2002; Arib, Sapuan, Ahmad, Tahir, \& Dahlan, 2006; 
Foo \& Hameed, 2009; Zainudin, Sapuan, Abdan, \& Mohamad, 2009; Hisham, Faieza, Ismail, Sapuan, \& Ibrahim, 2011; Ishak, Sapuan, Leman, Rahman, \& Anwar, 2011). Of all these residues, only a small proportion are used as household fuel or fertilisers and the remainder are considered as waste, which poses a negative effect for the environment (Chaudhary, 2004). Realistically, to make full use of these materials may not be viable, particularly in the immediate future; however, at least some of these materials can be used as fibres and fillers in polymer materials to form low profile composites (Sapuan, Harun, \& Abbas, 2007; Jeffrey, Tarlochan, \& Rahman, 2011; Bachtiar, Sapuan, \& Hamdan, 2010).

Unsaturated polyester (UP) resins are used extensively in the composites industry because of their good mechanical properties, low cost and ease of use (Horrocks, 2001; Bismarck, Mishra, \& Lampke, 2005). Ray and Rout (2005) stated that there are two main principles of polyester resins used as standard laminating systems in composites: orthophthalic and isophthalic polyester resins. Orthophthalic polyester resin is a standard economic resin, which yields products with high rigidity and low heat resistance. Isophthalic polyester resin is the preferred matrix material in the marine industry because it has superior water resistance. Combinations of the unsaturated polyester with natural fillers, such as oil palm ash, are believed to improve the mechanical and thermal properties of the composites. Utilisation of oil palm ash as a filler material in the manufacture of products, such as plastics, composites and concretes can significantly reduce the requirement for other binders or polymeric materials, or for other reinforcement of the composite materials. Globally, more than fifty million tons of fillers are consumed in various applications, such as paper, plastics, rubber, paint and adhesives with a combined value of approximately twenty-five billion Euros. It was also ranked among the raw materials, which are consumed and produced by suppliers and they are contained in a variety of goods for daily consumer needs.

The mechanical properties of composites made with natural fillers vary considerably depending on the physical and chemical properties and the composition of the material; the type of raw fibres and growth environment. It was stated that the mechanical properties of individual fibres from plants were much lower when compared with those of synthetic fibres. Natural fillers were originally taken from lignocellulosebased fibres and were widely used as biodegradable fillers. Considering environmental concerns, these natural fillers offer many advantages compared with manmade fillers, such as having low or no cost, high abundance, being a renewable resource and requiring low consumption of energy (Sapuan \& Maleque, 2005; Sahari, Sapuan, Ismarrubie, \& Rahman, 2011). In studying filled polymer composites, Hsu et al. (2001) proposed that the composites should have: good adhesion between the filler and matrix, a high modulus, low stress, minimal filler setting, low moisture absorption, fast cure and high durability or long lifetime. In order to fulfil those criteria, important considerations are: the percentage of filler loading, filler shape, the particle size distribution and the rate of filler dispersion in the matrix, because these affect the properties of filled composites. Fu, Feng, Lauke and Mai (2008) examined the effects of particle size, particle-matrix adhesion and particle loading on composite stiffness, strength and toughness. It was shown that composite strength and toughness were greatly affected by all three factors, especially the particle-matrix adhesion. Popa, Arnautu and Davydov (2002) emphasised that the mechanical adhesion, which represents the properties of the material, is correlated with the interfacial bonding between the filler and the matrix. Weakness of interfacial bonding leads to stress being transmitted to the filler through 
the matrix. Popa et al. (2002) also emphasised that the interface between the filler or reinforcing material and the polymeric matrix is essential in polymeric composites. The interface strengthens the mechanical resistance of composites and it is where the concentration of mechanical stress occurs because of the different properties of the matrix and the filler or reinforcing agent (Adebisi, Maleque, \& Rahman, 2011).

Amar, Abdulla, Satapathy, Sandhyarani, Bhabani \& Satapathy (2010) studied the thermal behaviour of particulate filled polymers. The objective of their research was to attain a better understanding of global and local thermal behaviour of a composite system, through the basics of thermal gravimetric analysis. Their study investigated the thermal conductivity of particulate filled reinforced polymer composites fabricated using two different manufacturing methods. The results clearly showed that an increase in filler concentration led to higher thermal conductivity, which can be correlated to the reduced dry sliding wear rate of the composites. Abdul Khalil, Firoozian, Bakare, Hazizan \& Ahmad Md Noor (2010) studied the development of natural filler of carbon black (CB), from bamboo stems, coconut shells and oil palm empty fibre bunches, which were obtained by pyrolysis of fibres at $700{ }^{\circ} \mathrm{C}$, characterised and used as filler in epoxy composites. The result of thermal gravimetric analysis showed that there was an improvement in thermal stability of the CB-filled composites compared with the pure epoxy resin. Realising the high cost of synthetic filler, attempts have been made to search for alternative fillers from agricultural waste. In this paper, a study of the mechanical and thermal properties of OPA-filled unsaturated polyester composites is presented.

\section{MATERIALS AND METHODS}

\section{Materials Preparation}

The raw material oil palm ash (OPA) was obtained from RISDA Palm Oil Mill, Ulu Keratong, Pahang, Malaysia. It was sieved to achieve filler particles smaller than $300 \mu \mathrm{m}$. Then, the filler was dried in an oven at a temperature of $250{ }^{\circ} \mathrm{C}$ for $3 \mathrm{hrs}$. The unsaturated polyester (UP), commercially known as Reversol P 9509 and its hardener, methyl ethyl ketone peroxide (MEKP) was supplied by Revertex (Malaysia) Sdn. Bhd, Kluang, Johor, Malaysia.

\section{Specimen Preparation}

Specimens were fabricated with different volume fractions, i.e., 0, 10, 20 and 30 vol.\% of oil palm ash in 100, 90, 80 and $70 \mathrm{vol} . \%$ of an unsaturated polyester matrix mixed with $1 \%$ hardener. The compounding of the matrix with the fillers was done using a mechanical stirrer for $1 \mathrm{hr}$ at $180 \mathrm{rpm}$. The compounded material was poured into a flat surface mould for preparing specimens of UP/OPA composites using the compression moulding technique. The moulds were left to cure at room temperature for $24 \mathrm{hrs}$. The specimens for tensile and flexural testing were prepared following the standards.

\section{Tensile Test}

The tensile test was performed according to ASTM D5083. The test was performed using an Instron 3366 universal testing machine, equipped with load capacity of $10 \mathrm{kN}$ 
at a deformation rate of $5 \mathrm{~mm} / \mathrm{min}$ and a gripping length of $100 \mathrm{~mm}$. The relative humidity (RH) and temperature in the testing room were maintained at $50 \%$ and $25{ }^{\circ} \mathrm{C}$, respectively. Replications with 10 specimens for each sample of composite were carried out.

\section{Flexural Test}

Prior to the flexural test, the samples were prepared according to ASTM D790, which requires samples to be $3 \mathrm{~mm}$ thick, $125 \mathrm{~mm}$ long and $10 \mathrm{~mm}$ wide, conditioned at a temperature of $25{ }^{\circ} \mathrm{C}$ with $\mathrm{RH}$ of $50 \%$ for a minimum $40 \mathrm{hrs}$ before testing. Flexural load on 3-point bending was used with the recommended testing span to the depth ratio of $16: 1$. Bending was conducted using a load cell of $5 \mathrm{kN}$ with a $2.8 \mathrm{~mm} / \mathrm{min}$ rate of loading. Replications with 10 specimens for each sample of composites were carried out.

\section{Scanning Electron Microscope (SEM) Analysis}

Morphological studies of the UP/OPA composites were carried out using a Philips XL30 SEM (Philips, UK). The deposited OPA particles were detected using backscattered secondary electrons (BSE) with a $15 \mathrm{keV}$ electron beam, at $300 \times$ magnification, a spot diameter of $5 \mu \mathrm{m}$, take off angle of $15^{\circ}$ and with an acquisition time of 60 s. Thermal Gravimetrical Analyser (TGA) and Differential Scanning Calorimeter (DSC) tests were performed concurrently using the Mettler Toledo TGA/DSC1. The tests were performed using an aluminium pan at a heating rate of $10{ }^{\circ} \mathrm{C} / \mathrm{min}$ in the temperature range of $0-1000^{\circ} \mathrm{C}$. Nitrogen flow at a rate of $50 \mathrm{~mL} / \mathrm{min}$ was kept constant throughout the experiments. The sample mass for each experiment was chosen to be between 6.01 and $12.01 \mathrm{mg}$.

\section{RESULTS AND DISCUSSION}

Table 1 presents the effects of increasing filler content on the results of tensile strength, flexural strength, tensile modulus, flexural modulus and elongation at break of the composite system.

Table 1. The effects of filler content on mechanical properties of the UP/OPA composites.

\begin{tabular}{cccccc}
\hline OPA content & $\begin{array}{c}\text { Tensile } \\
\text { strength } \\
(\mathrm{MPa})\end{array}$ & $\begin{array}{c}\text { Flexural } \\
\text { strength } \\
(\mathrm{MPa})\end{array}$ & $\begin{array}{c}\text { Tensile } \\
\text { modulus } \\
(\mathrm{MPa})\end{array}$ & $\begin{array}{c}\text { Flexural } \\
\text { modulus } \\
(\mathrm{MPa})\end{array}$ & $\begin{array}{c}\text { Elongation at } \\
\text { break } \\
(\%)\end{array}$ \\
\hline $0 \%$ & 26.8 & 88.48 & 375 & 200 & 4.55 \\
$10 \%$ & 21 & 78.17 & 390 & 210 & 3.11 \\
$20 \%$ & 17 & 71.7 & 435 & 218 & 2.22 \\
$30 \%$ & 13 & 62.5 & 499 & 224 & 1.26 \\
\hline
\end{tabular}

The relationship between tensile strength of UP/OPA composites with OPA loading is shown in Figure 1. Tensile strength of pure UP (26.8MPa) was decreased by the addition of OPA filler at $10 \%, 20 \%$ and $30 \%(21,17$ and $13 \mathrm{MPa})$ respectively. The 
decrease of tensile strength can be attributed to the physical properties of this filler and the interaction of this filler with the UP matrix (Moczo \& Pukanszky, 2008). Increasing the filler content for UP/OPA composites reduced the tensile strength of the composites, which can be attributed to the larger particles of the OPA $(300 \mu \mathrm{m})$. This is in agreement with the studies of Ibrahim, Faieza, Sapuan \& Tahir. (2011), who found that OPA particles had the tendency to form an agglomeration in humid conditions due to low surface interaction of the filler with the UP matrix. These agglomerated particles reduce the compatibility of the filler in the UP matrix and their capability to support stress transmitted from the UP matrix is relatively poor. These results, clearly observed with SEM analysis, which shows the fractured specimen due to low surface interaction between the OPA filler and the UP matrix, will be discussed later (Figure 7).

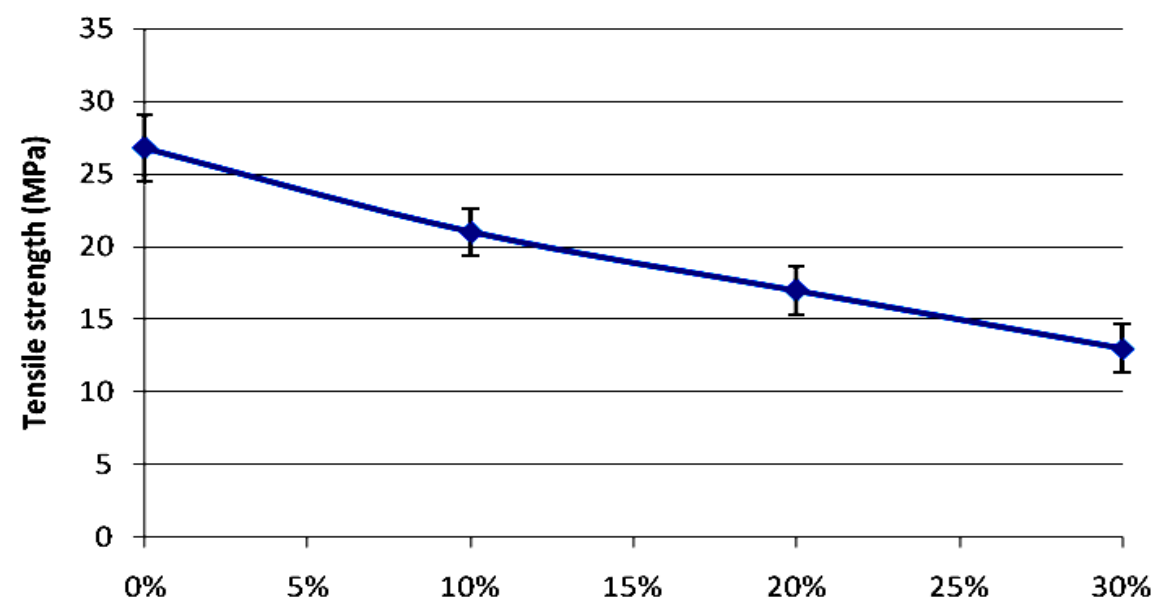

Figure 1. Effect of different filler content on tensile strength of UP/OPA composites.

A different trend to that found for tensile strength is observed for the tensile modulus. As the filler content is increased, the tensile modulus is increased (Figure 2). The tensile modulus of pure UP increased with the addition of $10 \%$ by volume of OPA in a UP/OPA composite. This trend continued when the OPA filler was increased from $20 \%$ to $30 \%$ by volume. According to Adams and Tsai (1969), the modulus indicates the relative stiffness of a material. The incorporation of a filler imparts greater stiffness to the composite. The incorporation of OPA has improved the stiffness of the UP matrix, because the tensile modulus of the composite increased as the OPA filler loading was increased (Figure 2).

Figure 3 shows the effect of OPA loading on the elongation at break of UP/OPA composites. The elongation at break, obtained from the tensile tests, indicates the elastic properties of the composites. Generally, a high value of elongation at break is indicative of a highly elastic material. The addition of filler causes the matrix to lose its elastic properties and the material becomes more brittle. Incorporation of OPA at 10\% into the UP matrix drastically reduces the value of the elongation at break. It was reported that the reduction of elongation at break of mica/epoxy composites was due to a reduction of the volume of the matrix (Suradi, Yunus, \& Beg, 2011), because the elastic properties were only obtained from the matrix (Firoozian, Hazizan, \& Khalil., 2010). This indicated that the incorporation of OPA in the UP matrix reduced the elasticity of the matrix, which led to composites that are more rigid. The rigidity of the composite was also due to the restriction of the mobility and deformability of the UP matrix by the 
addition of filler content. Thermoset UP-based composites are generally more brittle and have lower elasticity compared with epoxy-based composites (Ismail \& Ramli, 2008).

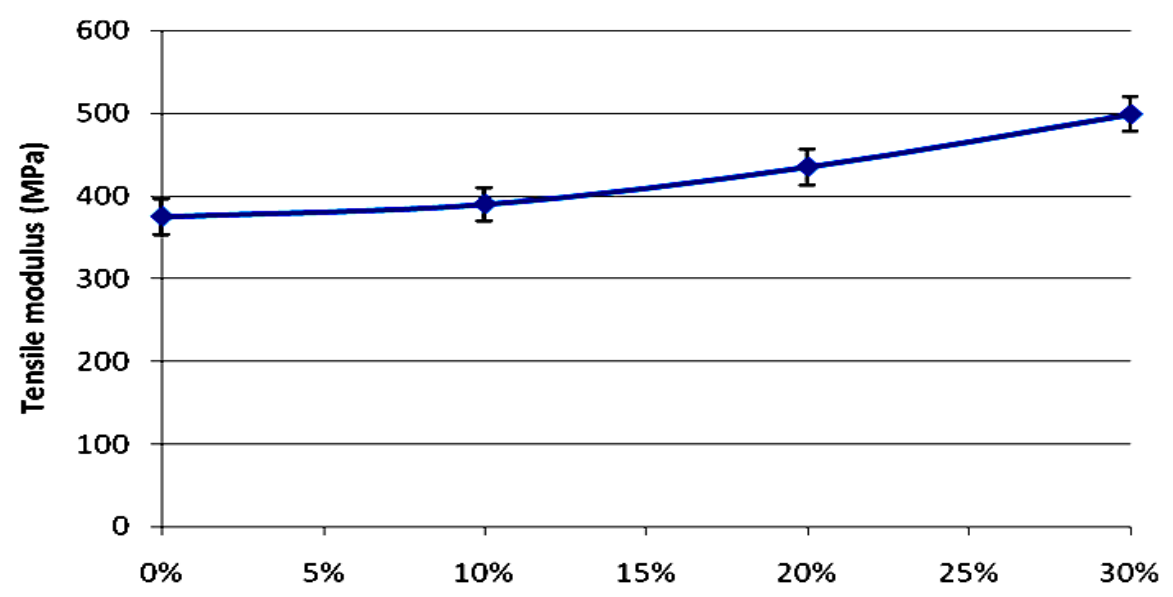

Figure 2. Tensile modulus of UP/OPA composites with different filler content.

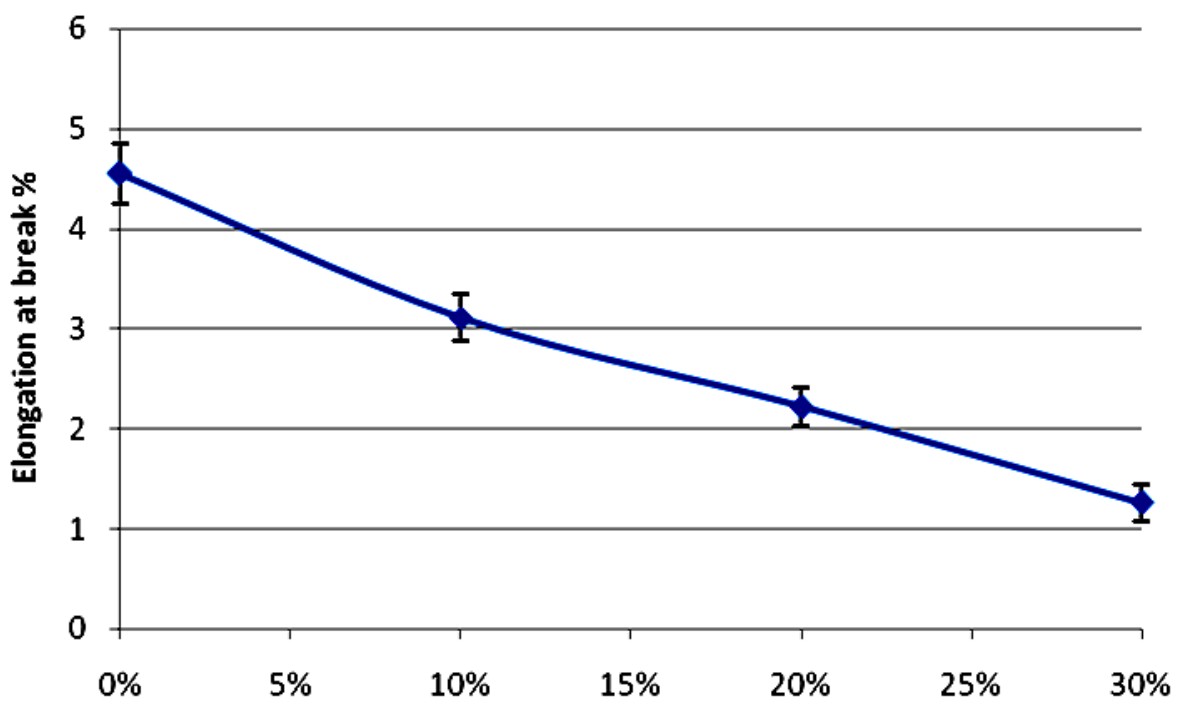

Figure 3. Effect of OPA loading on elongation at break of UP/OPA composites.

The flexural stress or strength, determined using a three point bending test, is given by Eq. (1):

$$
\sigma_{\text {max }}=\frac{\left(3 P_{\text {max }} L\right)}{\left(b h^{2}\right)}
$$

where $P_{\max }$ is the maximum load at failure (N), $L$ is the span in mm, $b$ and $h$ are the width and thickness of the specimen in $\mathrm{mm}$, respectively.

The results of the tests of flexural strength of the composite system as a function of filler loadings are presented in Figure 4. In general, the graph shows a decreasing trend as the OPA filler loading is increased. The flexural strength of the pure UP 
specimens decreased as the filler content of the UP/OPA composites was increased. The reason for this is that the surface adhesion between the UP matrix and the OPA filler is rather poor; in other words, there was less interfacial interaction between the OPA and the UP. The main component of the ash is silica, which provides low surface interaction with most of the polymers due to its chemical properties (Guyard, Persello, Boisvert, \& Bernard, 2006). The main idea in this study was to investigate the compatibility of OPA with the UP matrix, so that it can perform as filler for a polymer composite. Increasing the OPA content in the UP matrix necessarily means that the amount of UP matrix is decreased. The findings of the flexural properties have significance with regard to a reduction of the use of the binder. Due to the limited quantity of the binder or matrix, the UP resin was not able to completely wet the surface of filler even after the compounding process with the stirrer had been applied. Other observations were that agglomeration of fillers occurred during the compounding process and thus, disrupted the interfacial adhsion between the OPA and UP of the specimen. This was proven with SEM surface analysis, which will be discussed later (Figure 8).

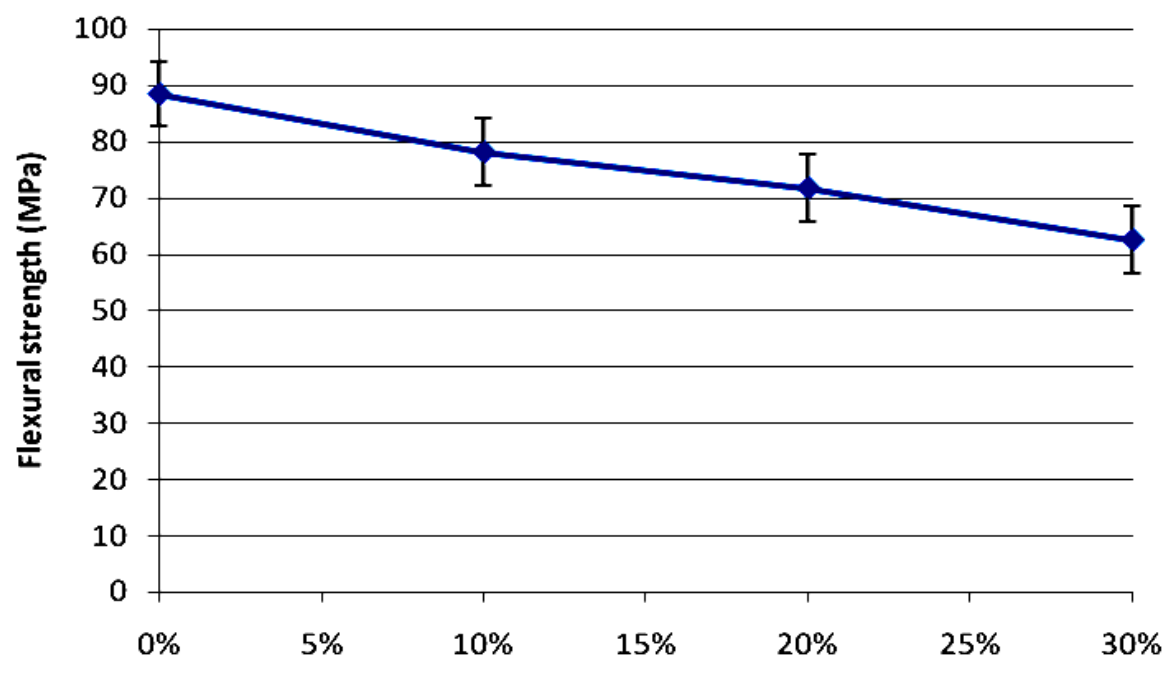

Figure 4. Effect of filler loading on flexural strength of UP/OPA composites.

The flexural modulus was defined as the ability of the material to maintain its original dimensions before being ruptured by the flexural load. The result of the flexural modulus for different filler contents of UP/OPA composites is shown in Figure 5. The modulus of the UP/OPA composite was increased with the addition of OPA filler, from a flexural modulus for pure UP of $200 \mathrm{MPa}$, to 212,222 and $233 \mathrm{MPa}$ for UP90/OPA10, UP80/OPA20 and UP70/OPA30, respectively. The increase of the modulus has significance for the stiffness properties of the UP/OPA composites. The modulus indicates the relative stiffness of a material. It was discussed earlier that incorporation of filler imparted greater stiffness to the composites. Incorporation of OPA improved the stiffness of the UP matrix, because the flexural modulus of the composites increased as the OPA loading was increased (Figure 5). Figure 6 shows the effect of the different content of filler on the surfaces of the UP/OPA composites. Figure 6(a) shows fewer particles filling the UP matrix with less agglomeration and fine dispersion of the filler. In Figure 6(b), the surface of UP80/OPA20 has some agglomeration of the OPA filler particles. The surface of UP70/OPA30 is shown in 
Figure 6(c) with a high number of particles filling the UP matrix, together with many agglomerated particles and voids.

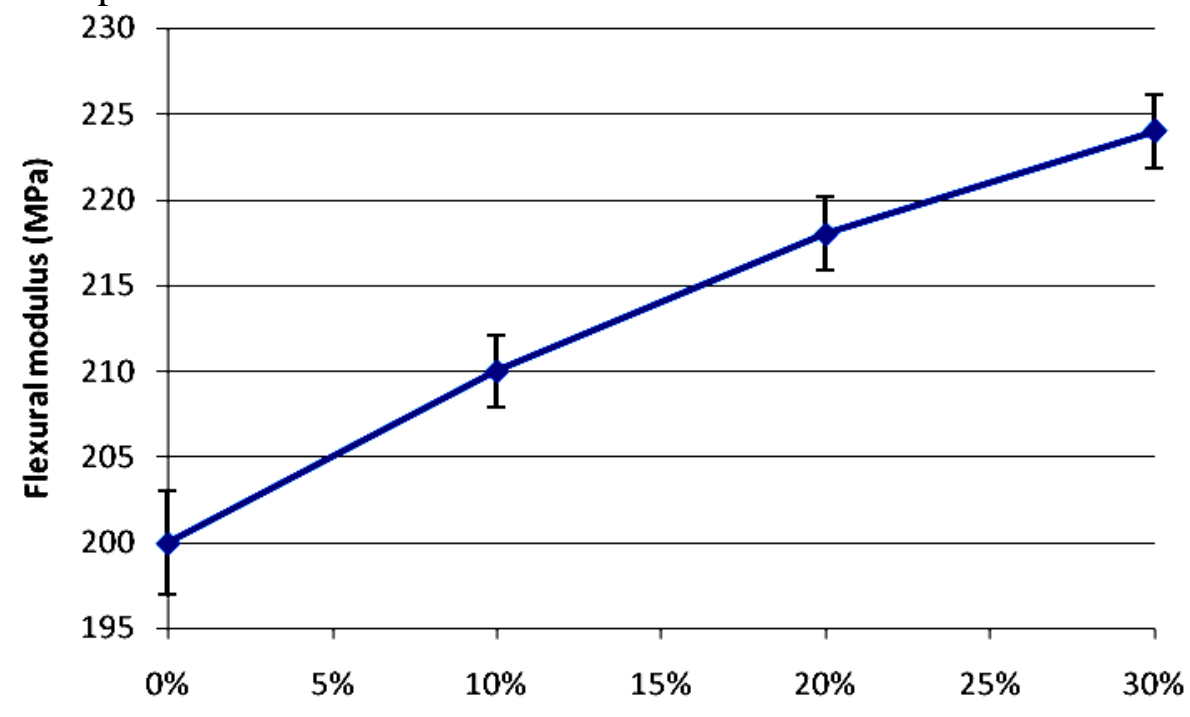

Figure 5. Effect of filler loading on flexural modulus of UP/OPA composites.

To understand the correlation of the mechanical tests with surface morphology, the fractured surfaces of the tensile and flexural tests were studied with SEM micrographs. Figures 7 and 8 show the fractured specimens of UP/OPA composite after tensile and flexural tests. These figures clearly show that the interaction of the filler and the matrix is low. With higher content of filler, the interactive stress fields compensating for the effect of stress concentration are low (Popa et al., 2002). The reduction of tensile strength is due to low surface interaction between the filler and the matrix, which creates voids that induce the initiation of cracks in the composite. The initiation cracks are caused because the tensile and flexural strength of the composites are decreased (Guyard et al., 2006). However, the incorporation of filler in the matrix could increase the stiffness of the UP/OPA composites, which results in an increase of the tensile and flexural modulus.

Figure 9 shows the TGA curves of the specimens of composites with several filler contents of OPA. The heating temperatures for the TGA were from $0-1000{ }^{\circ} \mathrm{C}$. The graph exhibits two mass loss steps; an initial mass loss was below $100{ }^{\circ} \mathrm{C}$, which was due to the gradual evaporation of moisture or water and a second mass loss from approximately $150-500{ }^{\circ} \mathrm{C}$, which was due to the decomposition of the polymeric material. In order to quantify what is the apparent and the actual effect of filler content on the thermal stability of the UP/OPA composites, the TGA curves were analysed as shown in Figure 9. Increasing the content of filler (OPA) in filled UP composites has a significant effect on the initial decomposition temperature (IDT). These values are determined as the temperature at which the amount of $5 \%$ of mass loss is initially observed. For each sample, the results are shown in Table 2. At temperatures above $500{ }^{\circ} \mathrm{C}$, the maximum thermal stability of UP filled with $10 \%$ OPA is much lower than that of UP filled with $20 \%$ and $30 \%$ OPA. This might be attributed to an inorganic component of oil palm ash that could act as a degradation protective layer at elevated thermal conditions. According to Bhat and Khalil (2010), ash in the OPA are mainly composed of silica, which has a resistance to high temperatures. 


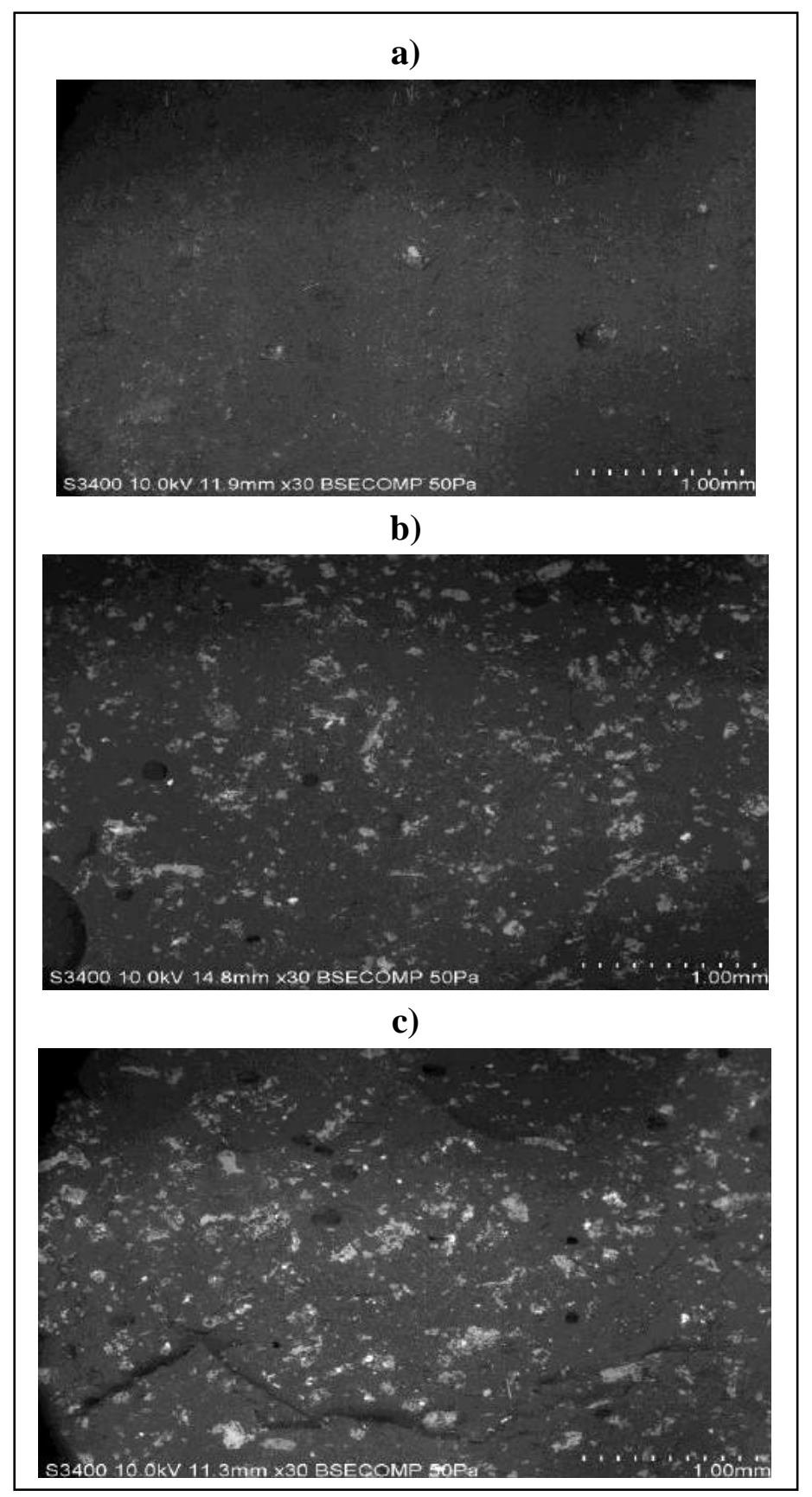

Figure 6. Surface morphology of: a) UP90/OPA10, b) UP80/OPA20, c) UP70/OPA30.

It was mentioned by Tarrio, Beceiro, Naya and Artiaga (2008) that thermal stability was slightly improved in a monotonic trend for silica content of $10 \%$ and $20 \%$. The amount and distribution of silica in the OPA has a significant effect on the properties of the composite products. It is inferred that silica content in the ash might be able to act as a trap of polymeric char (Liu, Wei, Hsu, \& Ho, 2004) or flame retardants (Hsiue, Liu, \& Liao, 2001). Figure 9 shows that UP filled with 30\% OPA exhibited slightly higher thermal stability than UP filled with $10 \%$ and $20 \%$ OPA. The increase of thermal stability of the composites was also due to the barrier effect of decomposition products by the dispersion of the OPA filler in the UP matrix. 


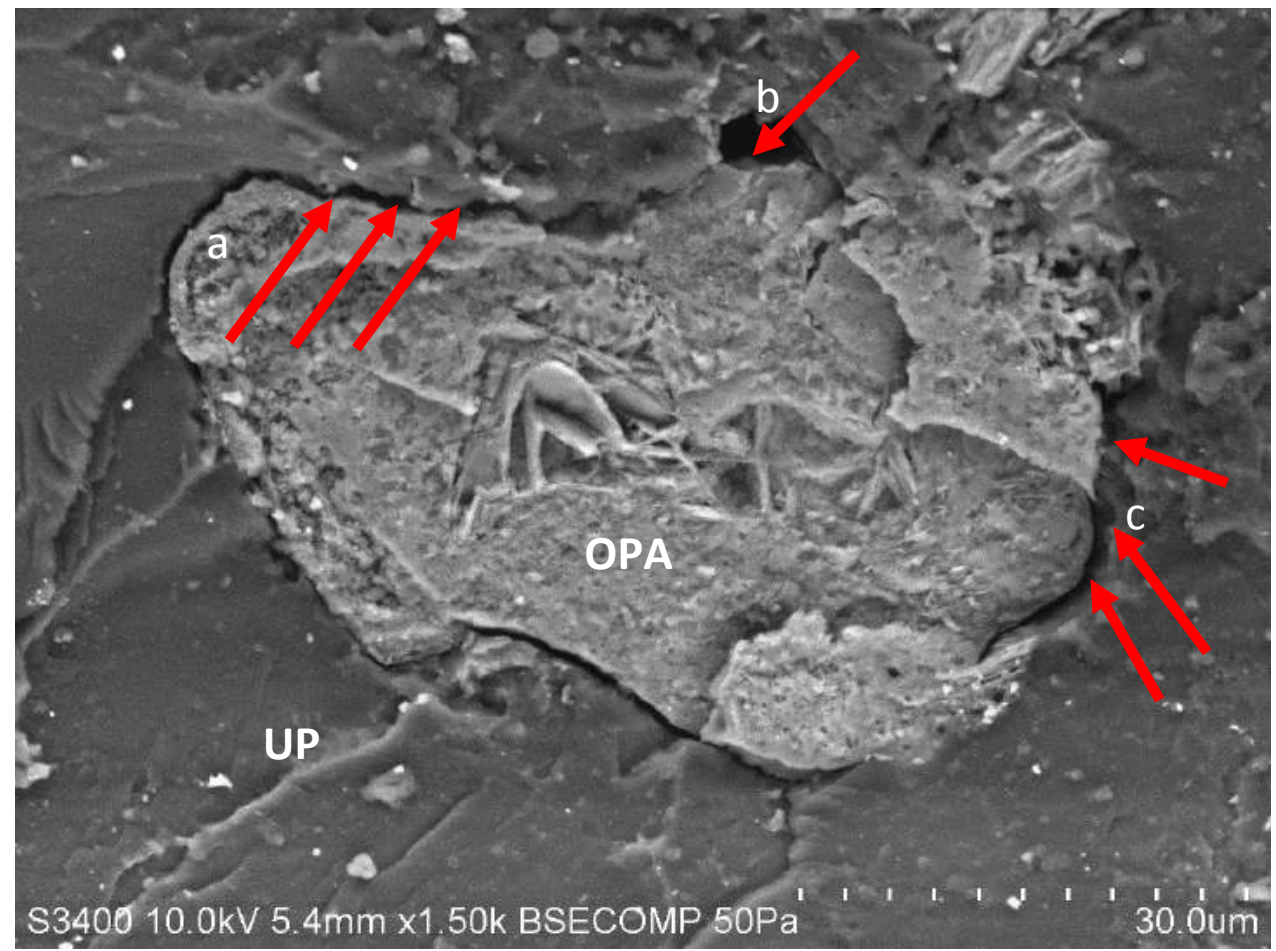

Figure 7. SEM micrograph of fractured surface on OPA/UP composites after tensile test shows: a) low surfaces interaction, b) voids and c) initial crack.

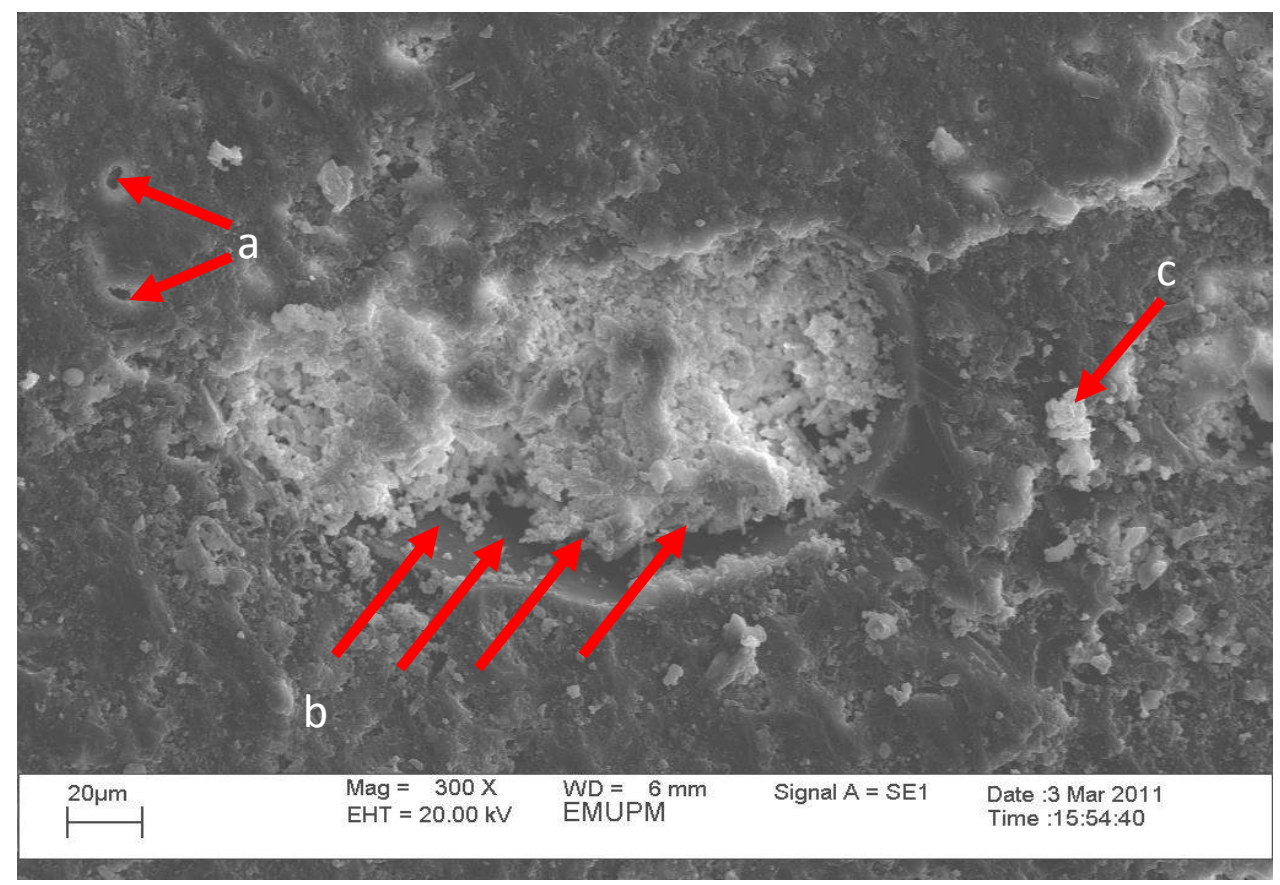

Figure 8. SEM micrograph of fractured surface on OPA/UP composites after flexural test shows: a) voids, b) low surfaces interaction and c) agglomeration of particles. 


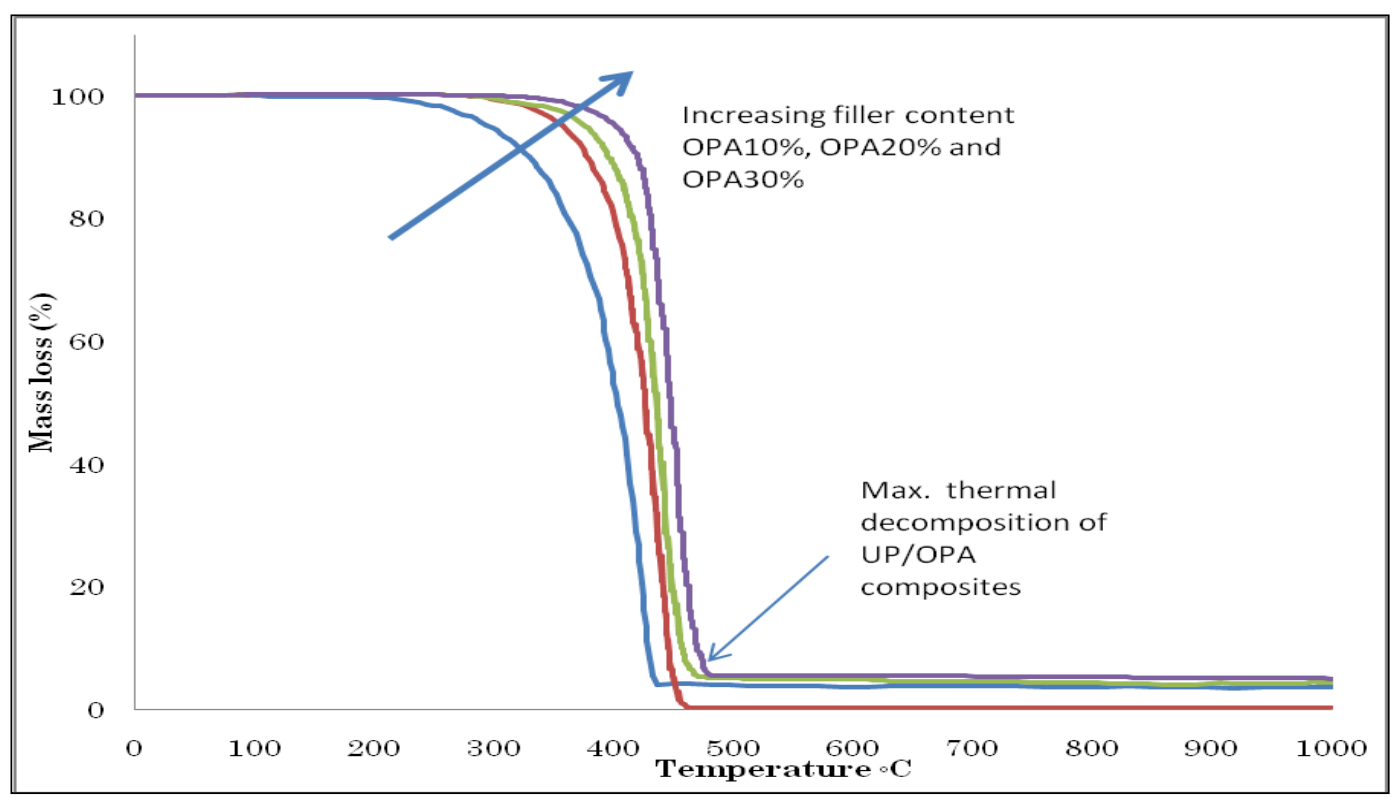

Figure 9. Analysis of TGA curves showed the effect of increasing filler content $(10 \%, 20 \%$ and $30 \%$ of OPA) in UP/OPA composites.

Table 2. Initial decomposition temperature IDT of UP/OPA composites from TGA curves.

\begin{tabular}{lc}
\hline \multicolumn{1}{c}{ Composite } & $5 \%$ mass loss IDT $\left({ }^{\circ} \mathrm{C}\right)$ \\
\hline UP & 293.55 \\
UP90/OPA10 & 356.64 \\
UP80/OPA20 & 375.59 \\
UP70/OPA30 & 401.72 \\
\hline
\end{tabular}

This result demonstrated that the thermal stability of UP/OPA composites was higher than that of neat UP. The thermal degradation of UP took place through random chain scission and a radical chain mechanism. However, the major source of thermal degradation in OPA was the degradation of chains of polymer that included $\mathrm{C}=\mathrm{C}$ (double bond chain). The maximum mass loss temperatures of the unsaturated polyester filled with different compositions of OPA are shown in the Table 3. The mass loss of neat UP took place very slowly at temperatures below $400{ }^{\circ} \mathrm{C}$ but above $400{ }^{\circ} \mathrm{C}$, this process occurred very rapidly. These results show that the thermal stability of the composite increased as the content of OPA filler was increased. This is a logical consequence of the high thermal stability of the silica compound of the OPA filler compared with that of UP matrix. The thermal degradation of the composite was retarded above $500{ }^{\circ} \mathrm{C}$ because of the increase in ash content. The DSC curves are shown in Figure 10. A run in the inert condition (nitrogen atmosphere) does not reveal any exothermic effect and thus, the thermal degradation of UP in the absence of oxygen (nitrogen atmosphere) must be related to the endothermic effect. Thermal stabilisation was observed by increasing the filler content up to $30 \%$ but no value for the optimal thermal stabilisation was obtained below that. At low filler content, the interfacial adhesion of polymer-filler dominates but the amount of exfoliated particles is not high enough to promote thermal stability through char formation (Boisvert, Guyard, Persello, 
\& Bernard, 2006). Thus, by increasing the filler content relatively more exfoliated particles are formed, and char forms more easily, which increases the thermal stability of the UP/OPA composite until a content of 30\% OPA filler is attained. The glass transition temperatures of the composites were increased but were similar because the gap between the curves in Figure 10 is rather small. The addition of filler content up to $30 \%$ in UP/OPA composites slightly increases the glass transition temperature $T g$ of the UP matrix from 185.4 to $191{ }^{\circ} \mathrm{C}$.

Table 3. Temperature of maximum mass loss rate, $\mathrm{T}_{\max }$ of UP/OPA composites from TGA curves.

\begin{tabular}{lc}
\hline \multicolumn{1}{r}{ Composite } & Temperature at max weight loss, $\mathrm{T}_{\max }\left({ }^{\circ} \mathrm{C}\right)$ \\
\hline UP & 436.64 \\
UP90/OPA10 & 460.90 \\
UP80/OPA20 & 468.01 \\
UP70/OPA30 & 476.23 \\
\hline
\end{tabular}

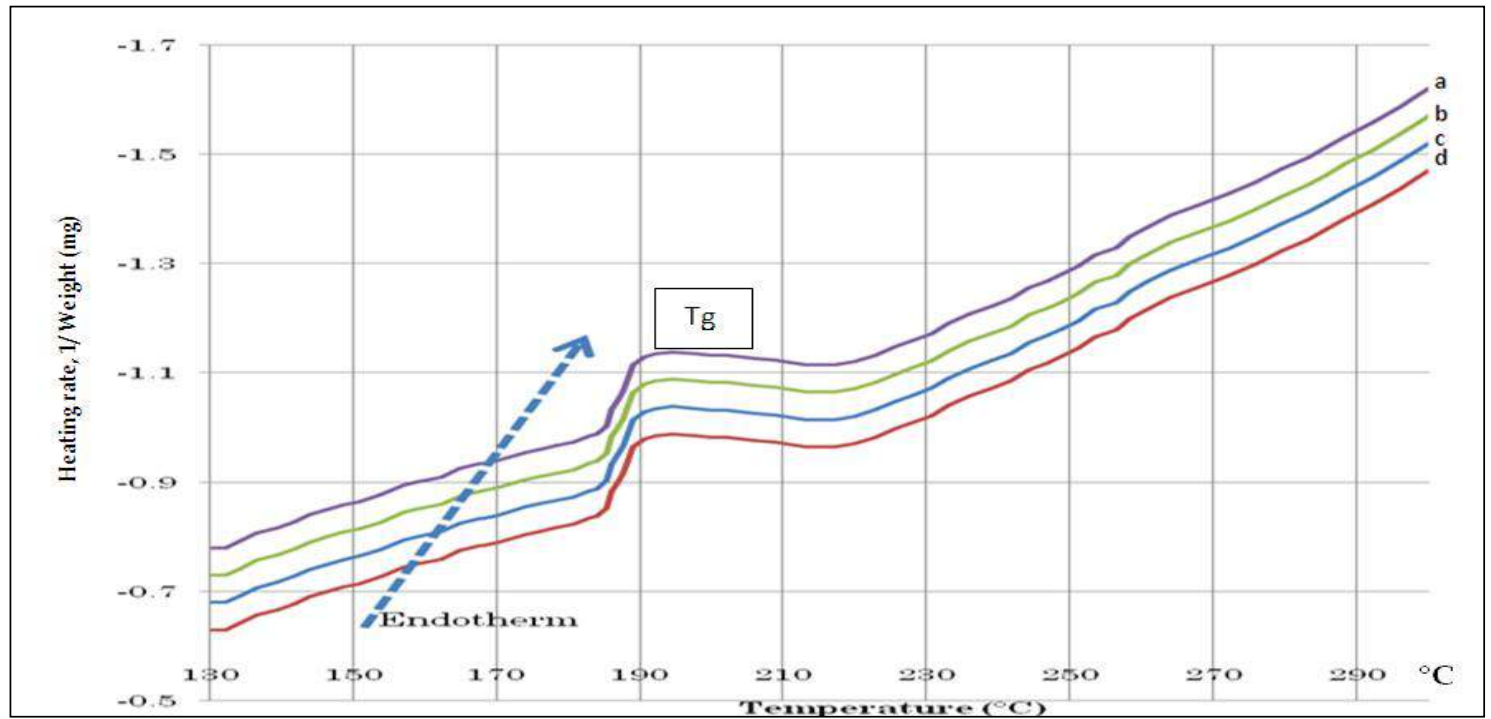

Figure 10. DSC curves of (a) UP100/OPA0, (b) UP90/OPA10, (c) UP80/OPA20 and (d) UP70/OPA30.

\section{CONCLUSIONS}

In general, the incorporation of OPA fillers in a UP matrix improved the modulus but there was a lack of tensile and flexural strength in the UP/OPA composites due to low surface interaction and non-uniformity of the stress transfer from the UP matrix to the OPA filler. Increasing the filler content led to agglomeration of particles in the matrix during the compounding of the OPA with the UP matrix. However, the stiffness of the UP/OPA composites increased relatively, which can be seen in the results of the tensile and flexural modulus. Generally, the UP/OPA-based composites were more brittle and 
had lower elasticity compared with composites with synthetic filler. The thermal stability of the composites increased as the OPA filler content was increased, which was a logical consequence of the high thermal stability of the silica compound of the OPA filler compared with that of the UP matrix. However, the thermal degradation of the composite was retarded above $500{ }^{\circ} \mathrm{C}$ because of the increase in ash content. With an increase of the filler content, the temperature of maximum mass loss of UP/OPA composites revealed an increasing trend: UP70/OPA30 $\left(476.23{ }^{\circ} \mathrm{C}\right)>\mathrm{UP} 80 / \mathrm{OPA} 20$ $\left(468.01{ }^{\circ} \mathrm{C}\right)>\mathrm{UP} 90 / \mathrm{OPA} 10\left(460.90{ }^{\circ} \mathrm{C}\right)>\mathrm{UP}\left(436.64{ }^{\circ} \mathrm{C}\right)$. The DSC studies showed that the glass transition temperature of the UP/OPA composite increased slightly from 185.4 to $191{ }^{\circ} \mathrm{C}$ with addition of filler content up to $30 \%$.

\section{ACKNOWLEDGEMENTS}

The authors would like to thank the Universiti Putra Malaysia for the financial assistance through Research University Grant Scheme (RUGS) project number 05-0109-0675.

\section{REFERENCES}

Abdul Khalil, H. P. S., Firoozian, P., Bakare, I. O., Hazizan, M. A., \& Ahmad Md Noor. (2010). Exploring biomass based carbon black as filler in epoxy composites: flexural and thermal properties. Materials and Design, 31, 3419-3425.

Adams, D. F., \& Tsai, S. W. (1969). The influence of random filament packing on transverse stiffness of unidirectional composites. Journal of Composite Materials, 3, 368-381.

Adebisi, A. A., Maleque, M. A., \& Rahman, M. M. (2011). Metal matrix composite brake rotor: historical development and product life cycle analysis. International Journal of Automotive and Mechanical Engineering, 4, 471-480.

Amar, P., Abdulla, M., Satapathy, A., Sandhyarani, B., Bhabani, \& Satapathy, K. (2010). A study on a possible correlation between thermal conductivity and wear resistance of particulate filled polymer composites. Materials and Design, 31, 837-849.

Arib, M. N., Sapuan, S. M., Ahmad, M. M. H. M., Tahir, P., \& Dahlan, K. Z. M. (2006). Mechanical properties of pineapple leaf fibre (PALF) reinforced polypropylene composites. Material and Design, 27, 391-396

Bachtiar, D., Sapuan, S. M., \& Hamdan, M. M. (2010). Flexural properties of alkaline treated sugar palm fibre reinforced epoxy composites. International Journal of Automotive and Mechanical Engineering, 1, 79-90.

Bhat, A. H., \& Khalil, H. P. S. (2010). Exploring nano filler based on oil palm ash in polypropylene composites. BioResources, 6, 1288-1297.

Bismarck, S., Mishra, M., \& Lampke, T. (2005). Plant Fibers as reinforcement for green composites. In A.M. Mohanty, Natural fibres, Biopolymers and Biocomposites (pp. 37-108). Boca Raton: CRC Press.

Boisvert, J. P., Guyard, A., Persello, J., \& Bernard, C. (2006). Relationship between the polymer/silica interaction and properties of silica compsite materials. Wiley InterScience, 44, 1134-1146.

Chaudhary, D. J. (2004). Recycling rice hull ash: A filler matrial for polymeric composites? Advances in Polymer Technology, 23,147-155. 
Firoozian, P., Hazizan, M. A., \& Khalil, H. P. S. A. (2010). Prediction of mechanical properties of mica-filled epoxy composite using various mechanical models. Journal of Reinforced Plastics and Composites, 29, 2368-2378.

Foo, K. Y., \& Hameed, B. H. (2009). Review: Value-added utilization of oil palm ash: a superior recycling of the industrial agricultural waste. Journal of Hazardous Materials, 172, 523-531.

Fu, S. Y., Feng, X. Q., Lauke, B., \& Mai, Y. W. (2008). Effects of particle size, particle/matrix interface adhesion and particle loading on mechanical properties of particulate-polymer composites. Composites: Part B, 39, 933-961.

Guyard, A., Persello, J., Boisvert, J. P., \& Bernard, C. (2006). Relationship between polymer/silica interaction properties of silica composite materials. Journal of Polymer Sciences Part B: Polymer Physics, 44, 1134-1146.

Hisham, S., Faieza, A. A., Ismail, N., Sapuan, S. M., \& Ibrahim, M. S. (2011). Tensile properties and micromorphologies of sawdust and chipwood filled epoxy composites. Key Engineering Materials, 471-472, 1070-1074

Horrocks, R. (2001). Composites. In A. R. Price, Fire Retardant Material (pp. 182-201). Cambridge, UK: Woodhead Publishing Ltd.

Hsiue, G. H., Liu, Y. L., \& Liao, H. H. (2001). Flame retardant epoxy resins: an approach from organic-inorganic hybrid nanocomposites. Journal of Polymer Science Part A: Polymer Chemistry, 92, 986-996.

Hsu, D. T. Kim, H. K. Shi, F. G. Tong, H. Y. Chungpaiboonpatana, S. Davidson, C.et al. (2001). Curing kinetics and optimal cure schedules for underfill materials. Journal of Microelectron Energy, 31, 271-275.

Ibrahim, M. S., Faieza, A. A., Sapuan, S. M., \& Tahir, S. M. (2011). Effect of filler loading and coupling agent on tensile and impact properties of polypropylene with oil palm ash composites. Key Engineering Material, 471-472, 1130-1135.

Ishak, M. R., Sapuan, S. M., Leman, Z., Rahman, M. Z. A., \& Anwar, U. M. K. (2011). Characterization of sugar palm (arenga pinnata) fibres: tensile and thermal properties. Journal of Thermal Analysis and Calorimetry, (in press)

Ismail, H., \& Ramli, R. (2008). Organoclay filled natural rubber nanocomposites: the effect of filler loading and mixing method. Journal of Reinfoced Plastics and Composites, 27, 1909-1924.

Jeffrey, K. J. T., Tarlochan, F., \& Rahman, M. M. (2011). Residual strength of chop strand mats glass fiber/epoxy composite structures: effect of temperature and water absorption. International Journal of Automotive and Mechanical Engineering, 4, 504-519.

Liu, Y. L., Wei, W. L., Hsu, K. Y., \& Ho, W. H. 2004. Thermal stability of epoxy-silica hybrid materials by thermogravimetric analysis. Thermochim ACTA , 412, 139147.

Moczo, J., \& Pukanszky, B. (2008). Polymer micro and nanocomposites: structure, interactions, properties. Journal of Industrial and Engineering Chemistry, 14, 535-563.

Oksman, K., Wallström, L., Berglund, L. \& Romildo, D. (2002). Morphology and mechanical properties of unidirectional sisal-epoxy composites. Journal of Polymer Sciences, 84, 2358-2365.

Popa, M., Arnautu, M., \& Davydov, Y. (2002). The interface in polymer matrix composites. In A.K. Kulshreshtha and C. Vasile, Handbook Of Poymer Blends And Composites (pp. 251-291). UK: Rapra Techn. Ltd. 
Ray, D., \& Rout, J. (2005). Thermoset biocomposites. In Natural Fibres, Biopolymers and Biocomposites (pp. 291-345). Boca Raton: CRC Press.

Sahari, J., Sapuan, S. M., Ismarrubie, Z. N., \& Rahman, M. Z. A. (2011). Comparative study of physical properties based on different parts of sugar palm fibre reinforced unsaturated polyester composites. Key Engineering Materials, 471472, 455-460.

Sapuan, S. M., \& Maleque, M. A. (2005). Design and fabrication of natural woven fabric reinforced epoxy composite for household telephone stand. Materials and Design, 26, 65-71.

Sapuan, S. M. Harun, N., \& Abbas, K. A. (2007). Design and fabrication of multipurpose table using a composite of epoxy and banana pseudo-stem fibres. Journal of Tropical Agriculture, 45(1/2), 66-68.

Suradi, S. S., Yunus, R. M., \& Beg, M. D. H. (2011). Oil palm bio-fibre-reinforced polypropylene composites: effects of alkali fibre treatment and coupling agents. Journal of Composite Materials, 45(18), 1853-1861.

Tarrio, J. S, Beceiro, J. L., Naya, S., \& Artiaga, R. (2008). Effect of silica content on thermal stability of fumed silica/epoxy composites. Polymer Degradation and Stability, 93, 2133-2137.

Zainudin, E. S., Sapuan, S. M., Abdan, K., \& Mohamad, M. T. M. (2009). Thermal degradation of banana pseudo-stem fibre reinforced unplastisized polyniyl chloride composites. Materials and Design, 30, 557-562. 